\title{
The effect of short-term dietary fibre administration on oro-caecal transit time in dogs
}

\author{
K.Papasouliotis, P.Muir, T. J. Gruffydd-Jones, P. J. Cripps and A. C. Blaxter \\ Department of Veterinary Medicine, University of Bristol, Langford, Bristol, UK
}

\begin{abstract}
Summary. The effect on oro-caecal transit time of addition of soluble (guar gum) and insoluble (wheat bran) fibre to diets fed to seven healthy dogs at levels that have been shown to reduce post-prandial hyperglycaemia was assessed. Oro-caecal transit time was measured by sequential analysis of exhaled breath hydrogen levels. Median oro-caecal transit times were $105 \mathrm{~min}$ (range: 45 to 135 ), $113 \mathrm{~min}$ (range: 53 to 203) and 105 min (range: 75 to 195 ) after administration of a $770 \mathrm{~g}$ standard meal of canned food alone, or with the addition of
\end{abstract}

$7.7 \mathrm{~g}$ wheat bran or guar gum, respectively. There was no significant difference between the oro-caecal transit times $(p=0.964)$ for the different diets when the results for all the dogs were pooled. The difference between diets was statistically significant for both maximal post-prandial hyperglycaemia $(p=0.035)$ and area of post-prandial hyperglycaemia under the post-prandial glucose curve $(p=0.006)$.

Key words: Breath, hydrogen, fibre, diabetes mellitus, dog.
Dietary fibre comprises a heterogeneous group of carbohydrate compounds derived from plant cell walls, including cellulose and hemicelluloses and a non-carbohydrate substance, lignin. Dietary fibre is not hydrolysed by enzymes of the gastrointestinal tract [1]. Certain substances are also considered part of the dietary fibre complex because of their similar dietary effects, although they are not true fibres [1,2]. These substances include guar gum, a gel-forming galactomannan obtained from the cluster bean (Cyanopsis tetragonal) and bran, which is derived from the outer layers of cereal grain seeds plus the inner, protein-rich aleurone layer.

It is now well established that increasing the viscous fibre content of the diet can reduce post-prandial hyperglycaemia in both humans [3, 4] and dogs [5]. The benefit of additional fibre in the long-term management of diabetes mellitus has been demonstrated in dogs with both experimentally-induced [6] and naturally-occurring diabetes [5]. The mechanism of this effect is still not clear, but may involve changes in intestinal transit times. Prolonged transit time will reduce the rate and delay the absorption of glucose from the small intestinal lumen [7].

Breath hydrogen analysis is a simple non-invasive technique that has been used to assess oro-caecal transit time which has been used in humans [8-12] and cats [13]. Colonic flora metabolize carbohydrate to produce hydrogen, some of which is absorbed into the circulation and released in the expired air [14-16]. Oro-caecal transit time
(OCTT) can therefore be assessed in healthy individuals by including non-absorbable carbohydrate in a test meal and determining the time taken for a sustained increase in exhaled hydrogen to occur $[13,17]$.

As manipulation of dietary fibre content has been shown to influence post-prandial hyperglycaemia in dogs with clinical diabetes [5], elucidation of the mechanism by which this occurs may provide important comparative information for the disease in humans. The purpose of this study was to investigate the effect on OCTT in healthy dogs of the addition of soluble (guar gum) or insoluble (wheat bran) fibre to a standard meal of canned food at levels which were shown to reduce post-prandial hyperglycaemia.

\section{Materials and methods}

\section{Animals}

Seven healthy Beagles of varying ages and sexes were used for the studies. The dogs had no recent history of gastrointestinal disease and ranged in weight from $10-15 \mathrm{~kg}$.

\section{Test protocols}

Dogs were tested following an overnight fast. Post-prandial glucose levels and breath hydrogen concentrations were assessed after the administration of three different approximately isocalorific 
Table 1. Nutritional analysis of the three test meals

\begin{tabular}{|c|c|c|c|c|c|c|c|}
\hline \multirow[t]{2}{*}{ Test meal } & \multirow{2}{*}{$\begin{array}{l}\text { Dry } \\
\text { matter } \\
\%\end{array}$} & \multirow{2}{*}{$\begin{array}{l}\text { Pro- } \\
\text { tein } \\
\%\end{array}$} & \multirow{2}{*}{$\begin{array}{l}\text { Fat } \\
\%\end{array}$} & \multirow{2}{*}{$\begin{array}{l}\text { Ash } \\
\%\end{array}$} & \multirow{2}{*}{$\begin{array}{l}\text { Carbo- } \\
\text { hydrate } \\
\%\end{array}$} & \multicolumn{2}{|c|}{ Dietary fibre } \\
\hline & & & & & & $\begin{array}{r}\text { soluble } \\
\%\end{array}$ & insoluble \\
\hline \multirow[t]{2}{*}{ STD } & \multirow[t]{2}{*}{15.9} & \multirow[t]{2}{*}{7.6} & \multirow[t]{2}{*}{4.2} & \multirow[t]{2}{*}{1.5} & \multirow[t]{2}{*}{1.5} & \multicolumn{2}{|c|}{1.1} \\
\hline & & & & & & 0.53 & 0.57 \\
\hline \multirow{2}{*}{$\begin{array}{l}\text { STD }+7.7 \mathrm{~g} \\
\text { wheat bran }\end{array}$} & \multirow[t]{2}{*}{16.6} & \multirow[t]{2}{*}{7.7} & \multirow[t]{2}{*}{4.2} & \multirow[t]{2}{*}{1.5} & \multirow[t]{2}{*}{1.8} & \multicolumn{2}{|c|}{1.4} \\
\hline & & & & & & 0.58 & 0.83 \\
\hline \multirow{2}{*}{$\begin{array}{l}\mathrm{STD}+7.7 \mathrm{~g} \\
\text { guar gum }\end{array}$} & \multirow{2}{*}{16.6} & \multirow[t]{2}{*}{7.6} & \multirow[t]{2}{*}{4.2} & \multirow[t]{2}{*}{1.5} & \multirow[t]{2}{*}{1.5} & \multicolumn{2}{|c|}{1.8} \\
\hline & & & & & & 1.04 & 0.76 \\
\hline
\end{tabular}

STD, Standard diet: $770 \mathrm{~g}$ Pedigree Chum Original, Pedigree Petfoods

Table 2. Oro-caecal transit times of different test meals in seven healthy dogs

\begin{tabular}{llll}
\hline Test meal & STD & $\begin{array}{l}\text { STD }+7.7 \mathrm{~g} \\
\text { wheat bran }\end{array}$ & $\begin{array}{l}\text { STD +7.7 g } \\
\text { guar gum }\end{array}$ \\
\hline $\begin{array}{l}\text { Median (min) } \\
\text { Range (min) }\end{array}$ & 105 & 113 & 105 \\
\hline
\end{tabular}

STD, Standard diet: 770 g Pedigree Chum Original, Pedigree Petfoods; Friedman test, $p=0.964$

Table 3. Maximal post-prandial hyperglycaemia in $\mathrm{mmol} / \mathrm{l}$ deviation from fasting glucose in seven dogs following three different test meals

\begin{tabular}{llll}
\hline Dog number & Test meal & & \\
\cline { 2 - 4 } & STD & $\begin{array}{l}\text { STD }+7.7 \mathrm{~g} \\
\text { wheat bran }\end{array}$ & $\begin{array}{l}\text { STD }+7.7 \mathrm{~g} \\
\text { guar gum }\end{array}$ \\
\hline 1 & 0.65 & 0 & 0 \\
2 & 0.92 & 0 & 0.26 \\
3 & 1.08 & 0.62 & 0 \\
4 & 0.70 & 0.48 & 0 \\
5 & 0.74 & 0.06 & 0.22 \\
6 & 1.04 & 1.09 & 0.48 \\
7 & 0.40 & 0.83 & 0 \\
\hline
\end{tabular}

STD, Standard diet: 770 g Pedigree Chum Original, Pedigree Petfoods

Table 4. Area of hyperglycaemia under the post-prandial glucose curve in seven dogs following three different test meals (in $\mathrm{cm}^{2}$ where $1 \mathrm{~cm}=10 \mathrm{~min}$ or $0.2 \mathrm{mmol} / 1$ glucose deviation)

\begin{tabular}{lccl}
\hline Dog number & Test meal & & \\
\cline { 2 - 4 } & STD & $\begin{array}{l}\text { STD + 7.7 g } \\
\text { wheat bran }\end{array}$ & $\begin{array}{l}\text { STD + 7.7 g } \\
\text { guar gum }\end{array}$ \\
\hline 1 & 8.90 & 0 & 0 \\
2 & 53.90 & 0 & 1.79 \\
3 & 65.50 & 32.80 & 0 \\
4 & 35.20 & 0.30 & 0 \\
5 & 5.70 & 1.90 & 0.75 \\
6 & 49.30 & 20.70 & 4.98 \\
7 & 3.40 & 11.50 & 0 \\
\hline
\end{tabular}

STD, Standard diet: $770 \mathrm{~g}$ Pedigree Chum Original, Pedigree Petfoods

( $616 \mathrm{kcal}$ metabolizable energy) test meals which were ingested within 2 min. The analysis of the three test meals used are shown in Table 1.

Assessment of post-prandial hyperglycaemia. On the day of trial an indwelling intravenous catheter was placed in each dog's cephalic vein. Blood samples were taken before and 10,20,30,60,90, 120,180,
240 min after the test meal. Plasma glucose was assayed on each sample by a routine biochemical assay using a centrifugal analyser (Diagnostica Cobas Bio; Roche Products Ltd., Herts., UK) within 30 to $240 \mathrm{~min}$ of sampling. The coefficient of variation for glucose was $4 \%$.

Assessment of oro-caecal transit time. Breath samples for hydrogen measurement were collected from each dog every 15 min for $3 \mathrm{~h}$ both in an unfed state and after the administration of the three test meals. The test protocol was completed twice for each meal in each $\mathrm{dog}$, with a minimum of $48 \mathrm{~h}$ between tests.

Collection of breath samples. Exhaled breath samples were collected using a semi-closed (chamber) system, previously described for use in cats [13] and adapted for dogs. During sampling, the dogs were confined in an acrylic plastic (Perspex; Amari Plastics, Bristol, UK) chamber measuring $50 \times 70 \times 50 \mathrm{~cm}$. Holes were drilled around the base of the box to allow air flow into the chamber. Air was continuously extracted from the top of the chamber by means of an air pump with a flow meter and a flow rate adjuster (IP-30L; Sibata Scientific Technology Ltd, Tokyo, Japan). The dilution of expired air was minimized and no respiratory distress was observed when an air flow rate of 10-15 litres per min was used. Air was passed from the outlet of the air pump through a flow transducer connected to a portable respiratory air monitor (Portable Respiratory Air Monitor; Harvard Apparatur Ltd, Edenbridge Kent, UK). The air monitor measures the volume of extracted air and automatically collects part of the air for a sampling period of $5 \mathrm{~min}$, into a multilaminated plastic bag.

Breath hydrogen excretion $(\mathrm{ml} / \mathrm{h})$ was calculated from the volume of air recorded by the air monitor, the sampling time set on the monitor, and the hydrogen concentration in duplicate air samples taken into $20 \mathrm{ml}$ plastic syringe from the collection bag.

Gas analysis. The concentration of hydrogen in the air samples was measured by a hydrogen monitor (GMI Exhaled Hydrogen Monitor; GMI Medical Ltd., Renfrew, UK) with an electrochemical detector, calibrated with a standard gas mixture.

\section{Statistical analysis}

Post-prandial hyperglycaemia. Maximal post-prandial hyperglycaemia and area of hyperglycaemia under the post-prandial glucose curve were calculated for each of the three test meals in the seven animals. Deviations from fasting blood glucose were also plotted against time. Statistical analysis of differences between test meals were assessed using the Friedman test ("non-parametric", equivalent to twoway analysis of variance). Each dog was considered as a "block" which provided one estimate of maximal post-prandial hyperglycaemia and one of area of hyperglycaemia for each test meal.

Oro-caecal transit time. Breath hydrogen concentrations follow an approximately log-normal distribution and were therefore $\log _{10}$ transformed [13] with results expressed as mean \pm SEM. Statistical analysis of differences between OCTT for each test meal were assessed using the Friedman test. Each dog was considered as a "block" which provided two estimates of transit time for each test meal. Using a previously described method [13], the OCTT was defined as the time from administration of the meal to the time when the cusum value for hydrogen excretion by the dog rose by $0.7 \mathrm{ml} \mathrm{hy}$ drogen/h or more, sustained for at least three successive readings. Results for OCTT were expressed as median, with ranges (Table 2).

\section{Results}

\section{Post-prandial hyperglycaemia}

The administration of standard meal resulted in hyperglycaemia over $60 \mathrm{~min}$ followed by a relative hypoglycaemia from 90 to $120 \mathrm{~min}$ (Fig. 1). The addition of guar gum abol- 


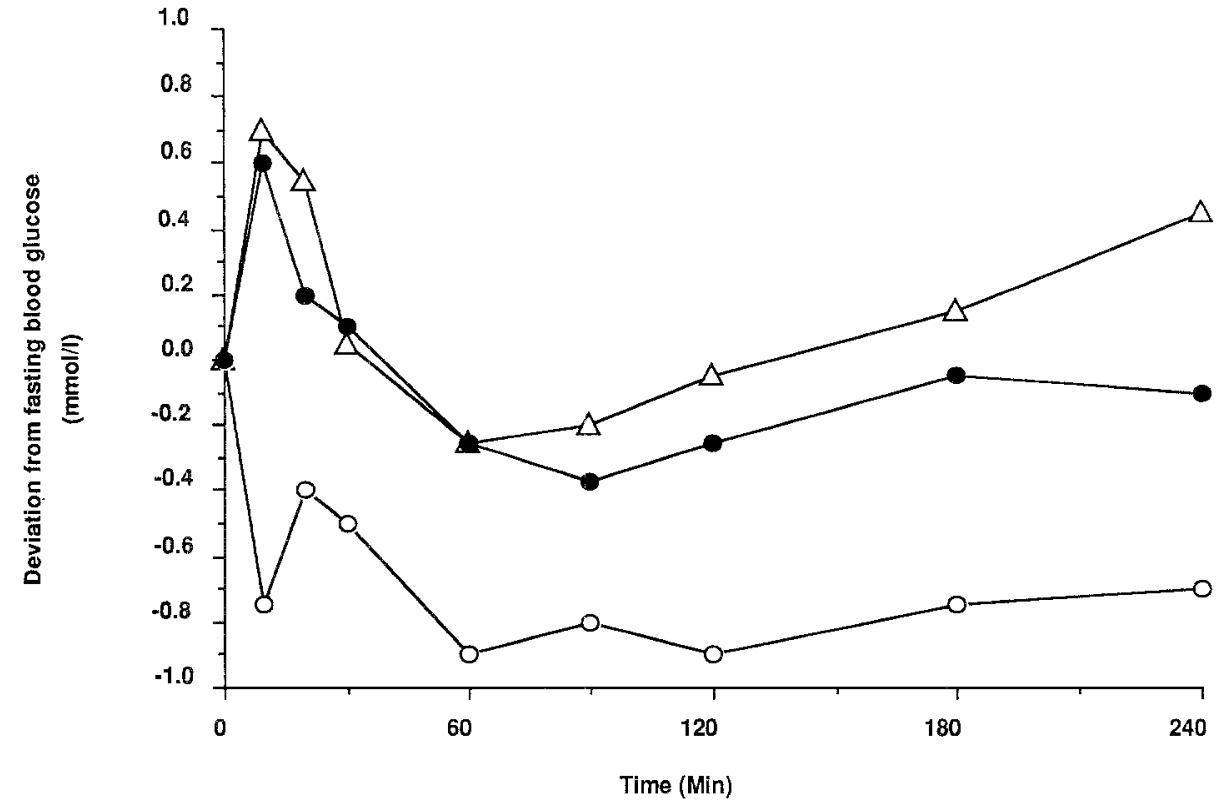

Fig. 1. Deviation (mean) from fasting blood glucose $(\mathrm{mmol} / \mathrm{l})$ in seven dogs after three different test meals. $\triangle-770 \mathrm{~g}$ standard meal, -0 -standard meal and 7.7 g guar gum, - -standard meal and $7.7 \mathrm{~g}$ wheat bran

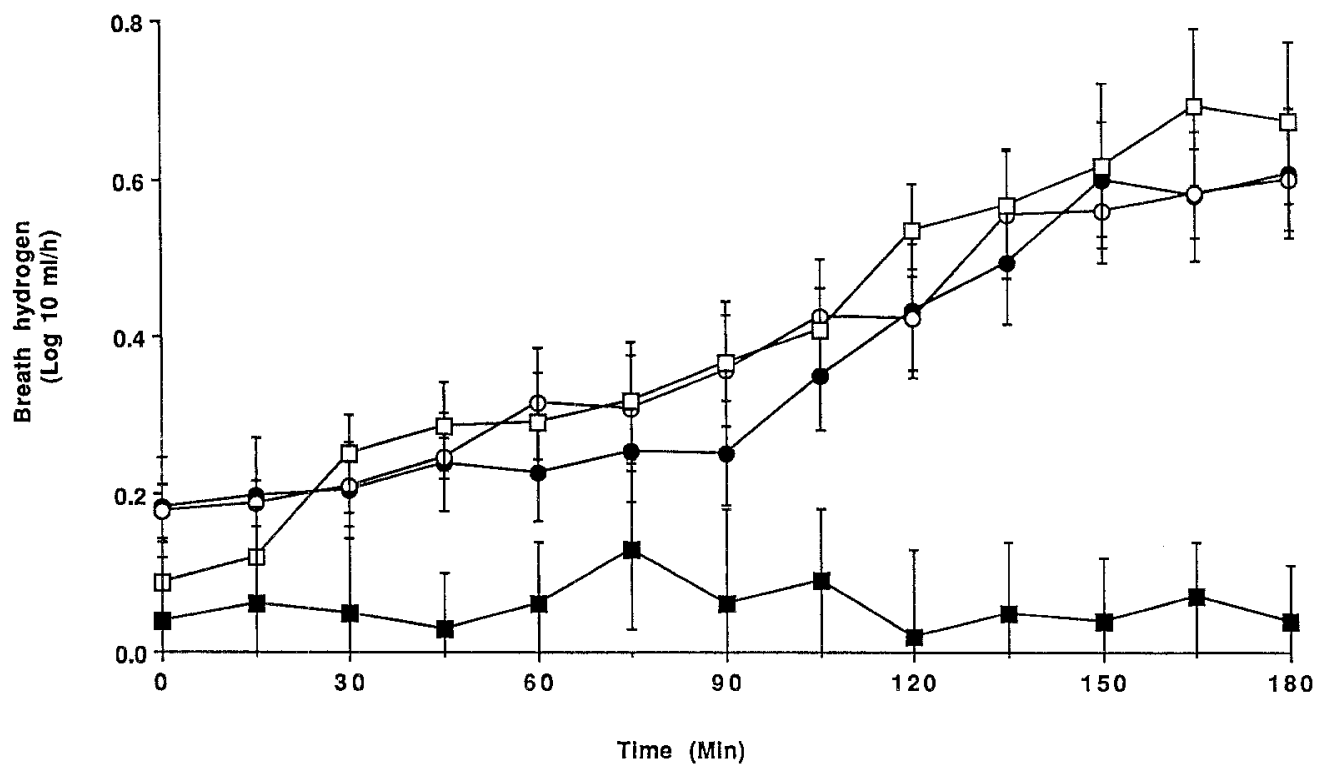

Fig. 2. Breath hydrogen concentrations in seven dogs not fed or fed the different test meals. - Fed standard meal and $7.7 \mathrm{~g}$ guar gum, $-\mathrm{O}-\mathrm{Fed}$ standard meal and $7.7 \mathrm{~g}$ wheat bran, $-\square-$ Fed $770 \mathrm{~g}$ standard meal, - -Not fed

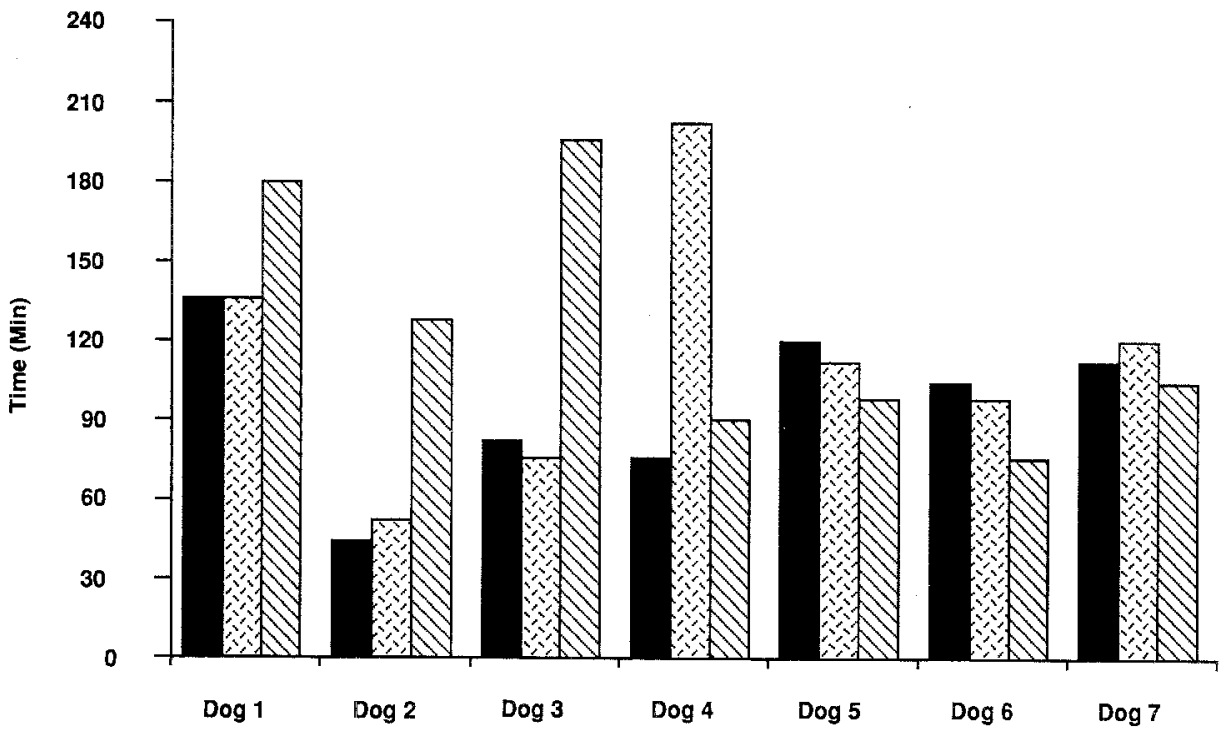

Fig. 3. Orocaecal transit time after different test meals, using the semiclosed (chamber) flow breath sample collection system. OCTT after standard meal, W OCTT after standard meal and wheat bran, $\triangle$ OCTT after standard meal an guar gum 
ished post-prandial hyperglycaemia in four animals and reduced the extent of hyperglycaemia in the remaining three. With the addition of wheat bran the maximal postprandial peak was also reduced, but to a lesser extent. The difference between diets (Tables 3 and 4) was statistically significant with $p=0.035$ for maximal post-prandial hyperglycaemia and $p=0.006$ for area of post-prandial hyperglycaemia. Further examination of these groups showed that the main difference was between the test meal containing guar gum and the standard meal.

\section{Breath hydrogen excretion}

Breath hydrogen concentrations in fasted dogs did not exceed $0.2 \log _{10} \mathrm{ml} / \mathrm{h}(1.58 \mathrm{ml} / \mathrm{h})$ during the 3 -h monitoring period. After the administration of the standard meal alone, with wheat bran and with guar gum, breath hydrogen excretion was significantly different from breath hydrogen excretion in fasting dogs (Fig. 2).

\section{Oro-caecal transit time}

Results of OCTTs following the different test meals are shown in Table 2 . There was no significant difference between the OCTTs ( $p=0.964)$ for the different diets when the results of all the dogs were pooled. However, differences were noted in some individual dogs. OCTTs in $\operatorname{dog} 1$ (135 vs $180 \mathrm{~min}$ ), $\operatorname{dog} 2$ (45 vs $128 \mathrm{~min}$ ) and $\operatorname{dog} 3$ (83 vs $195 \mathrm{~min}$ ) were clearly prolonged, after the administration of the standard meal with $7.7 \mathrm{~g}$ guar gum. OCTT was also prolonged in dog 4 (45 vs $203 \mathrm{~min}$ ) after the standard meal with $7.7 \mathrm{~g}$ wheat bran (Fig.3).

\section{Discussion}

Breath hydrogen excretion has been used to evaluate carbohydrate malassimilation in dogs $[18,19]$ but this is the first study, to our knowledge, to use breath hydrogen analysis to assess the effect of dietary fibre manipulation on OCTT in dogs. Earlier work investigating the effect of dietary fibre on intestinal transit time has often measured mouth to anus transit time which may not accurately reflect small intestinal transit time, since the former may be influenced by both gastric and colonic emptying times $[20$, 21].

The lactulose breath hydrogen test has been widely used as a non-invasive and simple method of determining small-intestine transit time [13,22-25]. The validity of this test for assessing OCTT has been established in comparative studies using radiography (barium sulphate meal) [24], scintigraphy [26] or radiopaque plastic markers [27]. Concentrations of breath hydrogen measured in fasted dogs were low which is in agreement with previous reports in man [28], dogs [18] and cats [13]. Mucus glycoproteins are believed to be a substrate for hydrogen production by colonic flora and the source of these low concentrations in the fasting state in man [29]. Breath hydrogen excretion increased after feeding the standard meal of canned food due to colonic fermentation of carbohydrates which had not been completely absorbed [19]. In previous studies lactulose has been added to test diets to ensure that identifiable increases in the quantity of hydrogen occur but this itself may accelerate OCTT $[17,30$, 31] and therefore these results would be less physiological.

Jenkins et al. [7] employed the breath hydrogen test to assess the OCTT in man using a basic meal consisting of $50 \mathrm{~g}$ glucose, $25 \mathrm{~g}$ xylose, $15 \mathrm{~g}$ lactulose and $40 \mathrm{~g}$ pure lemon juice in $400 \mathrm{ml}$ water and compared this with the OCTT after the addition of $14.5 \mathrm{~g}$ guar or $41.5 \mathrm{~g}$ wheat bran. Guar was found to delay and wheat bran to accelerate OCTT. In another study [32], dogs were fitted with jejunal cannulae and jejunal transit time was determined, after feeding a meal of canned food $(500 \mathrm{~g})$, from a dyedilution curve of phenosulphonphthalein in samples taken from the cannula. Wheat bran or guar gum $(30 \mathrm{~g})$ was added and comparison of jejunal transit times showed delay after feeding both these dietary fibres.

The quantities of dietary fibres used in our study produced significant decreases in post-prandial glucose concentrations. Our findings however, did not demonstrate any significant difference on OCTTs after feeding these dietary fibres. This may be explained by the higher doses of fibres and the different method for the assessment of OCTT that was used in the previous study of dogs [7] and the differences in the composition and viscosity of the test meals that were used in the study in man [32]. The measurement of breath hydrogen excretion every $15 \mathrm{~min}$ in our study may not have been sufficiently sensitive to detect small changes in OCTT, which did lead to a reduction in post-prandial hyperglycaemia. However, alteration in small intestinal transit time is not the only mechanism which might be responsible for reduction in post-prandial glucose concentrations. Guar and other soluble fibres can delay glucose absorption by increasing the thickness of the unstirred water layer [33,34], a layer immediately adjacent to the intestinal wall, which consists of a series of poorly mixed stationary lamellae [35] which many investigators consider to be composed mainly of mucin [36]. Feeding soluble fibres can also reduce the rate of glucose absorption in the small intestine by influencing small intestinal morphology and function, including decreasing brushborder sucrase and lactase concentrations [37]. Soluble fibres may also enhance tissue sensitivity to circulating insulin and through this mechanism reduce glucose concentrations [3]. Changes in mucin content or composition at the mucosal surface may lead to slowing of glucose absorption after feeding insoluble fibres such as wheat bran [32]. Wheat bran and other foods rich in insoluble fibre can also delay glucose absorption by reducing the rate of penetration of the food by digestive enzymes or inhibiting digestive enzymes, decreasing the rate of supply of glucose for absorption [38].

Dogs make a useful model for comparative studies of diabetes. Dietary modification with increased fibre levels has been shown to reduce post-prandial hyperglycaemia in dogs with naturally-occurring [5] and experimentallyinduced [6] diabetes. Dietary intake in dogs can be carefully controlled avoiding the problems of compliance that often occur in human studies. Dogs are prepared to accept 
restricted, monotonous diets over prolonged periods of time enabling long-term studies to be conducted. They therefore provide a valuable model for the investigation of the gastrointestinal mechanisms involved in alterations of post-prandial hyperglycaemia induced by dietary modifications.

Acknowledgements. K. Papasouliotis was in receipt of a study fellowship from the British Council.

\section{References}

1. Cummings JH (1973) Dietary fibre. Gut 14:69-81

2. Van Soest PJ (1978) Dietary fibers: their definition and nutritional properties. Am J Clin Nutr 31: S12-S20

3. Jenkins DJ, Leeds AR, Wolever TM et al (1976) Unabsorbable carbohydrates and diabetes: decreased post-prandial hyperglycaemia. Lancet I: 172-174

4. Jenkins DJ, Leeds AR, Gassull MA, Cochet B, Alberti KGMM (1977) Decrease in postprandial insulin and glucose concentrations by guar and pectin. Ann Int Med 86: 20-23

5. Blaxter AC, Cripps PJ, Gruffydd-Jones TJ (1990) Dietary fibre and post prandial hyperglycaemia in normal and diabetic dogs. $\mathbf{J}$ Small Animal Practice 31: 229-233

6. Nelson RW, Ihle SL, Lewis LD et al. (1991) Effects of dietary fiber supplementation on glycemic control in dogs with alloxaninduced diabetes mellitus. Am J Vet Res 52: 2060-2066

7. Jenkins DJ, Wolever TM, Leeds AR et al. (1978) Dietary fibres, fibre analogues, and glucose tolerance: importance of viscosity. BrMed J 1: 1392-1394

8. Read NW, Cann PA, Holgate AM, Ac-Janabi M (1984) Measurement of gastrointestinal transit in man. Ital J Gastroenterol 16: $42-45$

9. Van Wyk M, Sommers K, Steyn AGW (1985) Evaluation of gastrointestinal motility using the hydrogen breath test. Br J Clin Pharmac 20: 479-481

10. Brown NJ, Rumsey RDE, Read NW (1987) Adaption of hydrogen analysis to measure stomach to caecum transit time in the rat. Gut 28: 849-854

11. Staniforth DH, Rose D (1989) Statistical analysis of the lactulose/breath hydrogen test in the measurment of orocaecal transit: its variability and predictive value in assessing drug action. Gut 30: 171-175

12. Tobin MV, Fisken RA, Diggery RT, Morris AL, Gilmore IT (1989) Orocaecal transit time in health and in thyroid disease. Gut 30: 26-29

13. Muir P, Papasuliotis K, Gruffydd-Jones TJ, Cripps PJ, Harbour DA (1991) Evaluation of carbohydrate malassimilation and intestinal transit time in cats by measurement of breath hydrogen. excretion. Am J Vet Res 52: 1104-1109

14. Levitt MD (1969) Production and excretion of hydrogen in man. N Engl J Med 281: 122-127

15. Metz G, Gassul MA, Drasar BS, Jenkins DJA, Blendis LM (1976) Breath-hydrogen test for small-intestinal bacterial colonisation. Lancet I: 668-669

16. Kerlin P, Wong L, Harris B, Capra S (1984) Rice flour, breath hydrogen, and malabsorption. Gastroenterology 87: 578-585

17. Ladas SD, Latoufis C, Giannopoulou H, Hatziioannou J, Raptis S (1989) Reproducible lactulose hydrogen breath test as a measure of mouth-to-cecum transit time. Dig Dis Sc 34: 919-924

18. Washabau RJ, Strombeck DR, Buffington CA., Harrold D (1986) Use of pulmonary hydrogen gas excretion to detect carbohydrate malabsorption in dogs. J Am Vet Med As 189: 674-679

19. Washabau RJ, Strombeck DR, Buffington CA, Harrold D (1986) Evaluation of intestinal carbohydrate malabsorption in the dog by pulmonary hydrogen gas excretion. Am J Vet Res 6: 14021406
20. Findlay JM, Smith AN, Mitchel WD, Anderson AJB, Eastwood MA (1974) Effects of unprocessed bran on colon function in normal subjects and in diverticular disease. Lancet I: 146-149

21. Kelsay J (1978) A review of research of effects of fiber intake on man. Am J Cl Nutr 31: 142-159

22. Bond JH, Levitt MD (1974) Investigation of small bowel transit time in man utilizing pulmonary hydrogen $\left(\mathrm{H}_{2}\right)$ measurements. J Lab Clin Med 5: 546-555

23. Camboni G, Basilisco G, Borrani A, Bianchi PA (1988) Repeatability of lactulose hydrogen breath test in subjects with normal or prolonged oroceacal transit. Dig Dis Sci 33: 1525-1527

24. Hirakawa M, Lida M, Kohrogi N, Fujishima M (1988) Hydrogen breath test assessment of orocaecal transit time: comparison with barium meal study. Am J Gastr 83: 1361-1363

25. Read NW, Cann PA, Holgate AN, Al-Janabi MN (1984) Measurement of gastrointestinal transit in man. Ital J Gastroenterol 16: $42-45$

26. Caride VJ, Prokop EK, Trongale FJ, Buddoura W, Winchenbach K, McCallum RW (1984) Scintigraphic determination of small intestinal transit time: comparison with the hydrogen breath technique. Gastroenterology 86: 714-720

27. Armbrecht U, Jansen J, Eden S, Stockbrugger R (1986) Assessement of oro-caecal transit time by means of hydrogen $\left(\mathrm{H}_{2}\right)$ as compared with a radiological control method. Scand J Gastroenterol 21: 669-677

28. Kotler DP, Holt PR, Sosensweig NS (1980) Modfication of the breath hydrogen test: increased sensitivity for the detection of carbohydrate malabsorption. Clin Chim Acta 108: 189-194

29. Perman JA, Modler S (1982) Glycoproteins as substrates for production of hydrogen and methane by colonic bacterial flora. Gastroenterology 83:388-393

30. La Brooy SJ, Male P-J, Beavis AK, Misiewicz JJ (1983) Assessment of the reproducibility of the lactulose $\mathrm{H} 2$ breath test as a measure of mouth to caecum transit time. Gut 24: 893-896

31. Holgate AM, Read NW (1983) Relationship between small bowel transit time and absorption of a solid meal. Influence of metoclopramide, magnesium sulfate and lactulose. Dig Dis Sc 28: 812-819

32. Bueno L, Praddaude F, Fioramonti J, Ruckebusch Y (1981) Effect of dietary fiber on gastrointestinal motility and jejunal transit time in dogs. Gastroenterology 80: 701-707

33. Elsenhans B, Sufke U, Blume R, Caspary WF (1980) The influence of carbohydrate gelling agents on rat intestinal transport of monosaccharides and neutral amino acids in vitro. Clin Sci 59: 373-380

34. Johnson IT, Gee M (1981) Effect of gel-forming gums on the intestinal unstirred layer and sugar transport in vitro. Gut 22:398403

35. Csaky TZ (1984) Intestinal permeation and permeability: an overview. Handbook Exp Pharmacol 70: 51-59

36. Magee DF (1982) The unstirred water layer. Is there one? Gastroenterology 82: 821 (Letter)

37. Thomsen LL, Tasman-Jones C (1982) Disaccharidase levels of the rat jejunum as altered by dietary fiber. Digestion 23: 252-258

38. Isaksson G, Lundquist I, Ihse I (1982) Effect of dietary fibre on pancreatic enzyme activity in vitro. Gastroenterology 82: 918 924

Received: 6 August 1992

and in revised form: 26 October 1992

Dr. K.Papasouliotis

Department of Veterinary Medicine

University of Bristol

Langford House

Langford

Bristol BS18 7DU

UK 